\title{
Nghiên cứu đặc điểm hình thái vỡ xương sọ do tai nạn giao thông đường bộ qua giám định pháp $\mathrm{y}$
}

\author{
Nguyễn Tuấn Anh ${ }^{1}$, Lư Sỹ Hùng ${ }^{1, *}$, Nguyễn Văn Thoan², Phạm Hồng Thao ${ }^{3}$ \\ ${ }^{1}$ Bộ môn Y Pháp Truờng Đại học Y Hà Nội, số 1 Tôn Thất Tùng, Đống Đa, Hà Nội, Việt Nam \\ ${ }^{2}$ Bác sỹ nội trú Chuyên ngành Ngoại khoá 41, \\ Trưòng Đại học Y Hà Nội, số 1 Tôn Thẩt Tùng, Đống Đa, Hà Nội, Việt Nam \\ ${ }^{3}$ Viện Pháp Y Quân Đội, 1A Trần Thánh Tông, Hai Bà Trung, Hà Nội, Việt Nam
}

Nhận ngày 23 tháng 3 năm 2017

Chỉnh sửa ngày 26 tháng 4 năm 2017; Chấp nhận đăng ngày 14 tháng 6 năm 2017

\begin{abstract}
Tóm tắt: Vỡ xương sọ là tổn thương hay gặp trong các vụ tai nạn giao thông đường bộ, giám định Y- Pháp được thực hiện nhằm xác định nguyên nhân tử vong và cơ chế gây thương tích. Nghiên cứu được thực hiện tại khoa Giải phẫu bệnh - Pháp Y bệnh viện Việt Đức trong thời gian từ 01/01/2013 đến 30/8/2015 trên 100 nạn nhân tử vong do TNGTĐB có tổn thương vỡ xương sọ. Nạn nhân nhỏ tuổi nhất là 8 tuổi, nạn nhân lớn tuổi nhất là 78 tuổi. Độ tuổi trung bình là 28.5 tuổi, gặp nhiều nhất là nạn nhân 22 tuổi. Nam giới chiếm đa số (74\%), nữ giới chiếm $26 \%$, vỡ xương thành nhiều mảnh chiếm tỷ lệ $14,51 \%$, vỡ xương hình đường thẳng là $36,29 \%$. Tổn thương vỡ xương bên đối diện là $13,71 \%$. tổn thương xương thái dương là $32,65 \%$ và $30,61 \%$ có tổn thương xương nền sọ.
\end{abstract}

Từ khóa: Tai nạn giao thông, chấn thương sọ não, vỡ xương sọ, vỡ xương bên đối diện, giám định Pháp y.

\section{1. Đặt vấn đề}

Vỡ xương sọ là sự phá huỷ tại một hoặc nhiều xương sọ, là tổn thương hay gặp trong các vụ tai nạn giao thông đường bộ (TNGTĐB). Trong chấn thương sọ não nặng, mảnh xương vỡ có thể bị di chuyển và làm tổn thương mạch máu ở màng não hoặc xé rách màng não dẫn đến chảy máu hoặc tổn thương não, muộn hơn nữa có thể gây nhiễm trùng, động kinh, mất trí sau chấn thương...

Chức năng của giám định Y- Pháp (GĐYP) trong các vụ TNGT là xác định nguyên nhân tử vong, cơ chế gây thương tích, dựng lại hiện

\footnotetext{
Tác giả liên hệ. ĐT.: 84-945963399.

Email: drlshung@gmail.com

https://doi.org/10.25073/2588-1132/vnumps.4056
}

trường vụ tai nạn và nghiên cứu đặc điểm tổn thương của những nạn nhân tử vong nhằm tìm ra những biện pháp phòng tránh TNGT phù hợp nhất, đồng thời giúp các thầy thuốc lâm sàng trong chẩn đoán, hồi sức cấp cứu, tiên lượng và điều trị những người bị tai nạn được tốt hơn. Tuy nhiên trên thực tế ở nước ta, việc khám nghiệm tử thi không phải lúc nào cũng thuận lợi do nhiều nguyên nhân chủ quan và khách quan, dẫn đến chất lượng giám định không cao, đã có nhiều vụ việc giám định viên không giải thích được cơ chế hình thành dấu vết thương tích và nguyên nhân tử vong của nạn nhân, do vậy đã gây không ít khó khăn cho công tác điều tra xét xử và đặc biệt là góp phần tìm ra những nguyên nhân và giải pháp nhằm làm giảm bớt số vụ tai nạn giao thông. 
Xuất phát từ thực trạng của tình hình trên, đề tài "Nghiên cứu đặc điểm hình thái vỡ" xương sọ do tai nạn giao thông đường bộ qua giám định y pháp tại bệnh viện Việt Đức" được thực hiện với mục tiêu "Phân tích đặc điểm hình thái tổn thương võ xương sọ trong những trường hơp chết vì TNGTĐB đường bộ".

\section{2. Đối tượng và phương pháp nghiên cứu}

\section{1. Đối tượng nghiên cưu}

Là những nạn nhân tử vong do TNGTĐB có kèm theo tổn thương vỡ xương sọ được giám định tại Khoa giải phẫu bệnh - Pháp Y bệnh viện HN Việt Đức từ 01/01/2013 đến 30/8/2015.

\subsection{Phuoong pháp nghiên cứu}

Nghiên cứu mô tả hồi cứu: trên 60 hồ sơ giám định từ 01/01/2013 đến 30/8/ 2014

Nghiên cứu mô tả tiến cứu: Tiến hành giám định $\mathrm{Y}$ pháp 40 trường hợp từ 01/9/2014 đến 30/8/2015.

Xử lý số liệu: Số liệu được xử lý bằng phần mềm thống kê SPSS 16.0

\section{Kết quả nghiên cứu}

3.1. Phân bố về tuổi và giới của các nạn nhân

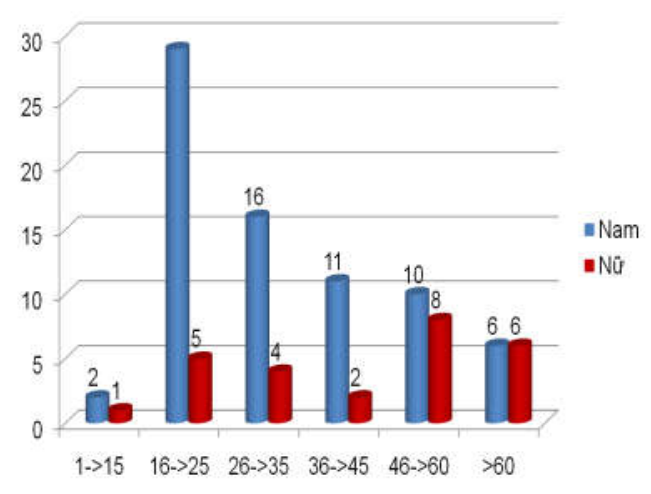

Biểu đồ 3.1. Phân bố về tuổi và giới của các nạn nhân.
Nhận xét:

- Nạn nhân nhỏ tuổi nhất là 8 tuổi, nạn nhân lớn tuổi nhất là 78 tuổi. Độ tuổi trung bình là 28.5 tuổi, gặp nhiều nhất là nạn nhân 22 tuổi.

- Nam giới chiếm đa số (74\%), Nữ giới chiếm $26 \%$.

\subsection{Thời gian sống sau tai nạn}

Bảng 3.2. Thời gian sống sau tai nạn.

\begin{tabular}{lll}
\hline Giờ & $\mathrm{n}$ & Tỷ lệ \% \\
\hline $\begin{array}{l}\text { Tử vong tại chỗ hoặc trên } \\
\text { đường đi cấp cứu }\end{array}$ & 55 & 55,0 \\
$<6 \mathrm{~h}$ & 19 & 19,0 \\
6h-12h & 10 & 10,0 \\
12h-24h & 7 & 7,0 \\
24h-48h & 2 & 2,0 \\
$48 \mathrm{~h}-72 \mathrm{~h}$ & 1 & 1,0 \\
$>72 \mathrm{~h}$ & 6 & 6,0 \\
Tổng & 100 & 100,0 \\
\hline
\end{tabular}

Nhận xét: Đa số nạn nhân tử vong ngay tại hiện trường $(55 \%)$ hoặc trên đường đi cấp cứu $(19 \%), 10 \%$ được cấp cứu và điều trị nhưng cũng tử vong trong vòng $6 \mathrm{~h}-12 \mathrm{~h}$.

\subsection{Hình thái tổn thuơng xuơng sọ}

Bảng 3.3. Hình thái tổn thương xương sọ đơn thuần

\begin{tabular}{lll}
\hline Hình thái đường vỡ & $\mathrm{n}$ & Tỷ lệ \% \\
\hline Vỡ đường thẳng & 45 & 36,29 \\
Vỡ hình sao & 5 & 4,05 \\
Vỡ hình mạng nhện & 2 & 1,61 \\
Vỡ nhiều mảnh & 18 & 14,51 \\
Vỡ lún & 37 & 29,83 \\
Vỡ hình tròn & 0 & 0 \\
Vỡ bên đối diện & 15 & 13,71 \\
Tổng số & 122 & 100 \\
\hline
\end{tabular}

Nhận xét: Hình thái vỡ xương thành nhiều mảnh chiếm tỷ lệ $14,51 \%$, vỡ xương hình đường thẳng là $36,29 \%$. Tổn thương vỡ xương bên đối diện chiếm tỷ lệ 13,71\%. 


\subsection{Vị trí tổn thương xương so}

Bảng 3.4. Vị trí tổn thương xương sọ

\begin{tabular}{lll}
\hline Vị trí & $\mathrm{n}$ & Tỷ lệ \% \\
\hline Trán & 38 & 19,39 \\
Đỉnh & 8 & 4,09 \\
Thái dương & 64 & 32,65 \\
Chẩm & 26 & 13,26 \\
Nền sọ & 60 & 30,61 \\
Tổng số & 196 & 100,0 \\
\hline
\end{tabular}

Nhận xét: Hay gặp nhất là tổn thương xương thái dương chiếm tỷ lệ $32,65 \%$, xương trán chiếm 19,39\% tiếp theo là xương chẩm $13,26 \%$, xương đỉnh ít tổn thương nhất chiếm $4,09 \%$. Có 30,61\% có tổn thương xương nền sọ.

\section{Bàn luận}

4.1. Một số đặc điểm dịch tễ của võ xuơng so do tai nạn giao thông đường bọ

\subsubsection{Tuổi và giới}

Tỷ lệ CTSN do TNGTĐB tăng nhiều trong những năm gần đây. Trong tổng số 100 nạn nhân chúng tôi nghiên cứu đa số là nạn nhân nam (74\%), nạn nhân nữ chiếm $26 \%$. Số lượng nạn nhân nam cao gấp gần 3 lần nạn nhân nữ. Đây là đặc điểm được hầu hết các tác giả trong nước ghi nhận. Nguyễn Phương Hoa và Phạm Thị Lan [4] nam giới là $78,9 \%$, nữ chiếm 21,1\%. Đồng Văn Hệ và các cộng sự [5] cũng ghi nhận tỷ lệ nạn nhân nam 79,4\%, nữ 20,6\%.

Trong nghiên cứu của chúng tôi, số lượng nạn nhân ở độ tuổi 16 - 60 chiếm đến $85 \%$. Nhóm tuổi 16 - 25 chiếm nhiều nhất (34\%), tiếp theo là nhóm 26 - 35 (20\%), nhóm 36 - 45 chiếm 13\%, nhóm trên 60 tuổi là $12 \%$. Nạn nhân nhỏ tuổi nhất là 08 tuổi, nạn nhân lớn tuổi nhất là 78 tuổi. Độ tuổi trung bình là 28,5 tuổi, gặp nhiều nhất là nạn nhân 22 tuổi.

\subsubsection{Thời gian sống sau tai nạn}

Dựa theo phân loại của hiệp hội Ngoại khoa Hoa Kỳ (ATLS), thời gian tử vong của nạn nhân bị tai nạn được chia thành 3 nhóm là: (1) Chết ngay sau tai nạn đến trước 30', (2) Sau 30 phút đến trước $3 \mathrm{~h}$ và (3) Sau $3 \mathrm{~h}$ đến một vài ngày, một vài tuần. Trong 100 đối tượng nghiên cứu, đa số nạn nhân tử vong tại hiện trường hiện trường hoặc đang trên đường đi cấp cứu (74\%) hoặc có được cấp cứu điều trị nhưng tử vong trong 6 giờ đầu (10\%). Trong số 55 trường hợp tử vong tại chỗ thì $94,5 \%$ có vỡ xương sọ thành nhiều mảnh, $72,7 \%$ có bẹp biến dạng hộp sọ.

\section{2. Đặc điểm tổn thuơng xuơng sọ}

4.2.1. Đặc điểm hình thái tổn thương xương sọ

Đường vỡ xương sọ xuất hiện nhiều nhất là vỡ theo đường thẳng chiếm $36,29 \%$ các loại đường vỡ xương, vỡ lún chiếm $29,83 \%$, thấp nhất vỡ theo hình mạng nhện $1,61 \%$. Tỷ lệ này phù hợp với một số nghiên cứu của nước ngoài. Theo M. J. Shkrum and D. A. Ramsay [2] phần lớn $(43 \%)$ là vỡ xương theo đường thẳng hoặc gẫy vụn. Theo Ahmad $M$ và cộng sự [9] đường vỡ theo đường thẳng là chủ yếu chiếm $36 \%$, các dạng khác từ $2-18 \%$.

Số liệu trong nghiên cứu của chúng tôi ghi nhận vỡ xương nền sọ là $30,61 \%$ với hầu hết các đường vỡ nền sọ đi qua những điểm yếu nhất của nền sọ. Tùy theo vị trí tác động của ngoại lực mà có thể gây ra một số đường vỡ khác nhau. Trong nghiên cứu này chúng tôi xếp loại đường vỡ theo phân loại của Michael $\mathrm{J}$. Shkrum [1].

\subsubsection{Vị trí tổn thương xương sọ}

Trong số các xương bị tổn thương nhiều nhất là xương thái dương 32,65\%, tiếp theo là xương trán $(19,39 \%)$, xương chẩm $(13,26 \%)$ và ít nhất là xương đỉnh $(4,09 \%)$. Tổn thương xương nền sọ chiếm $30,61 \%$. Trong đó tổn thương phối hợp nhiều xương có $65 \%$, vỡ 1 xương xuất hiện $35 \%$. Tỷ lệ này phù hợp với các nghiên cứu ở nước ngoài. Theo Ahmad. $\mathrm{M}$ [9] vỡ xương thái dương chiếm nhiều nhất $32 \%$, xương chẩm $15 \%$, xương trán $19 \%$, xương đỉnh $7 \%$.Theo $\mathrm{BR}$ Sharma và cộng sự [8] tỷ lệ vỡ xương sọ là $88,01 \%$, vỡ nhiều xương $62 \%$, vỡ 
một xương chiếm 38\%. Theo Gupta Prashant K và cộng sự [10] tỷ lệ vỡ xương sọ $62 \%$. Theo Kaleem Ahmad và cộng sự [7] vỡ xương sọ xuất hiện trong $57,75 \%$ các trường hợp. Điều đó phần nào cho thấy vỡ xương sọ gây ra những tổn thương nghiêm trọng dẫn đến tử vong.

\section{Kết luận}

Phần lớn nạn nhân chết do TNGTĐB có tổn thương vỡ xương sọ là nam giới, chiếm $74 \%$. Số nạn nhân trong độ tuổi 16 - 60 là $85 \%$, nhiều nhất là nhóm tuổi 16 - 25 chiếm $34 \%$. Đa số nạn nhân tử vong tại chỗ (55\%), nguyên nhân tử vong chủ yếu là CTSN nặng $70 \%$.

Vị trí vỡ xương hay hay gặp nhất là xương thái dương với tỷ lệ $32,65 \%$, vỡ nền sọ là $30,61 \%$.

Hình thái tổn thương hay gặp là vỡ xương thành đường thẳng $(36,29 \%)$, vỡ xương sọ thành nhiều mảnh $14,51 \%$ và vỡ lún $29,83 \%$. Vỡ xương bên đối diện gặp 13,71\% các trường hợp. Không ghi nhận trường hợp nào vỡ xương hình tròn trong nghiên cứu này.

\section{Tài liệu tham khảo}

[1] Michael J. Shkrum (2006), The Forensic Pathology of Trauma.
[2] M. J. Shkrum và D. A. Ramsay Forensic Pathology of Trauma: Common Problems for the Pathologist.

[3] Vũ Ngọc Tú và Đồng Văn hệ (2004). Đặc điểm lâm sàng và cận lâm sàng chấn thương sọ não nặng, Tạp chí Y học thực hành, 491, 298 - 303.

[4] Nguyễn Phương Hoa và Phạm Thị Lan (2012). Tử vong do tai nạn giao thông đường bộ tại một số tỉnh, Tạp chí nghiên cứu Y học, 80(3c)

[5] Đồng Văn Hệ, Trần Trường Giang, Phạm Tân Thành et al (2005). Đặc điểm dịch tễ học chấn thương sọ não tại Bệnh viện Việt Đức, Tạp chí nghiên cứu Y học, 39(6).

[6] Islam $\mathrm{RN}$, Monsur $\mathrm{MA}$ và Asaduzzaman $\mathrm{M}$ (2011). An Analysis of 100 Road Traffic Accident Victims, Dinajpur Med Col, 4(2), 67 - 70.

[7] Dr. Kaleem Ahmad, Dr. RK Rauniyar, Dr. Sajid Ansari et al (2013). Spectrum of various patterns of injuries in cranio-cerebral trauma: CT evaluation Indian Journal of Basic and Applied Medical Research, 3(1), 321 - 327.

[8] BR Sharma, D Harish, MBBS et al (2003). Patterns of Fatal Head Injuryn Road Traffic Accidents, Bahrain Medical Bulletin, 25(1), No 1.

[9] Ahmad M, Rahman FNC, Chowdhury MH et al (12. 2009). Postmortem study of head injury in fetal road trafic acidents, JAFMC Bangladesh 5(2), $24-28$

[10] Gupta Prashant K, Krishna Atul, Dwivedi Amit $\mathrm{N}$ et al (2011). CT Scan Findings and Outcomes of Head Injury Patients: A Cross-Sectional Study, J PAK MED STUD. jpmsonline.com, 1(3), 78-82.

\title{
Morphology Study of Fractured Skull Due to Road Trafic Accident through Forensic Medicine Examination
}

\author{
Nguyen Tuan Anh ${ }^{1}$, Luu Sy Hung ${ }^{1}$, Nguyen Van Thoan ${ }^{2}$, Pham Hong Thao ${ }^{3}$ \\ ${ }^{I}$ Dept of Forensic Medicine, Hanoi Medical University, No 01, Ton That Tung Str, Dong Da, Hanoi, Vietnam \\ ${ }^{2}$ Surgery resident doctor, 41 Hanoi Medical University, \\ 01 Ton That Tung, Dong Da, Hanoi, Vietnam \\ ${ }^{3}$ Institute of Military Forensic medicine, No 01 ${ }^{A}$, Tran Thanh Tong Str, Hai Ba Trung, Hanoi,Vietnam
}

Abstract: Fractures of the skull is the most common injuries in Road traffic accidents, and
forensic examination was conducted to determine the cause of death and mechanism of the injuries. 
The study was performed at the Department of Histo-Pathology and Forensic Medicine of Viet-Duc hospitals during the period from 01.01.2013 to 30.08.2015 in 100 victims, all they have fractured skull injury. The youngest victim was 8 years old and the oldest was 78 years old. The average age is 28.5 years old, most of vitims was 22 years. Most of victims were men (74\%), Women accounted for $26 \%$. fractured into pieces proportion of $14.51 \%$, simple linear fractures was $36.29 \%$ and contre - coup fractures was $13.71 \%$. temporal bone lesions proportion $32.65 \%$, Basilar skull fractures was $30.61 \%$.

Keywords: Road trafic accident, head injurie, skull fracture, contre - coup fractures, forensic exam. 